Acta Cryst. (2002). A58 (Supplement), C168

\section{MECHANISMS AND KINETICS OF MIXED CRYSTAL FORMATION (BY AN EXAMPLE AQUA SOLUBLE SALTS)}

L. Yu. Kryuchkova A. E. Glikin

Saint-Petersburg State University Geological Faculty Crystallography Universitetskaja Emb. 7/9 SAINT-PETERSBURG 199034 RUSSIA

Mixed crystal formation is characterized by specific phenomena and mechanisms what is urgent to reconstruct a mineral origin and to grow such crystals. The following processes including their joint development are observed in supercooled mixed solutions: dissolution, replacement, metastable heterogeneous equilibrium, and direct growth. A thermostatic vessel was used for visual observations and quantitative measurements of the processes in the ternary aqueous system with Co-Ni Tutton salts. Volume-deficit and volumeexcess replacement reactions were investigated during the interactions of the various mixed solutions and the end-member crystals of the isomorphic series. The phenomena mechanisms are interpreted in terms of the concept of multimineral-metasomatic crystallogenesis with help of modified Schreinemakers phase diagrams. Such combined morphological-kinetic investigations of mixed crystal formation are carried out for the fist time. In a general case of mixed crystal formation the ratios of the replacement and growth varies in a wide range depended on the crystal/solution compositions and the supercooling. A replacement is changed by a growth the faster the supercooling is higher. The characteristic supercooling of the growth without a replacement stage (the position of the metastable equilibrium) the versus the solution composition reaches a maximum around the equal quantity of the isomorphic components in the solution. In the case of a pure isomorphic replacement in a solution saturated by another isomorphic component, the rate of the process is slowed down during the course for all the solution compositions. These processes cause formation of unordinary spongy-like and epitaxy-excrescenced pseudomophs at volume-deficit and volume-excess replacement reactions respectively.

Keywords: CRYSTALLOGENESIS, ISOMORPHISM, MINERALOGY
Acta Cryst. (2002). A58 (Supplement), C168

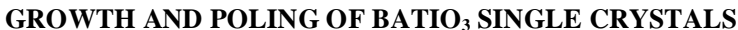

\section{T.K. Lee H.J. Park S.J. Chung}

Seoul National University School of Materials Science and Engineering Gwanak-Gu Shinlim-Dong San 56-1 SEOUL 151-742 SOUTH KOREA

$\mathrm{BaTiO}_{3}$ single crystals were grown by the top-seeded solution growth technique. The solution was composed of $33.5 \mathrm{~mol} \% \mathrm{BaO}$ and $66.5 \mathrm{~mol} \%$ $\mathrm{TiO}_{2}$. The observed surface roughening temperature was in the temperature range of $1370-1380^{\circ} \mathrm{C}$ in this solution. The grown crystals were yellowish, transparent and about 2-3 cm in size. The spatial domain configurations in the grown crystals were observed under a polarizing microscope, transmission electron microscope and by X-ray topography. In the poling process of the grown crystals, pressing, heating and applying of electric field were taken simultaneously according to a poling schedule on a house-made poling apparatus. The elimination of $90^{\circ}$ domain boundaries could be confirmed under a polarizing microscope. The refractive indices of as-grown crystals and the poled crystals are compared each other to examine the quality of the grown crystals. The dielectric constant of the poled specimen according to the frequency was measured to be certificate the single domain and the transmission was measured with UV-VIS-NIR spectrophotometer to search the optical applicability.

\section{Keywords: BATIO3, POLING, OPTICAL PROPERTY}

\section{Acta Cryst. (2002). A58 (Supplement), C168}

CATALYSED GROWTH OF DOPED LATGS SINGLE CRYSTALS J. Novotny Z. Podvalova J. Zelinka

Institute of Radio Engineering and Electronics Optoelectronics Chaberska 57 Praha 8 Academy of Sciences of The Czech Republic PRAGUE 18251 CZECH REPUBLIC

Triglycine sulphate $\left(\mathrm{NH}_{2} \mathrm{CH}_{2} \mathrm{COOH}\right)_{3} \cdot \mathrm{H}_{2} \mathrm{SO}_{4}$ single crystals (TGS) have been and still are important materials for the fabrication of infrared detectors and target part of vidicons operating at room temperature ${ }^{1}$. Single crystals of TGS with L-alanin (LATGS) doped with $\mathrm{Pr}^{3+}, \mathrm{Pd}^{2+}, \mathrm{Co}^{2+}, \mathrm{Pt}^{4+}$ and $\mathrm{PO}_{4}{ }^{3-}$ were grown from aqueous solutions by means of the slow cooling method. Surface morphology, domain structure and P-E hysteresis loops have been investigated. On the basis of observed data we performed the analysis of the rate of growth of $\langle 001\rangle,\langle 010\rangle$ and $\langle 001\rangle$ crystal growth pyramids. Enhancement of the (001) face growth rate of doped LATGS crystals is apparently due to the presence of metal cations in the growth solution. We developed a model of the catalytic action of metal ions on the transfer processes of the crystal growth units on the basis of observed results ${ }^{2}$. In the paper we show that the preparation of doped LATGS single crystals by complex-creating metal ions is very suitable for the growth of the high-volume non-polar growth pyramids used for infrared applications. For this purpose we designed and realized a special flow-type crystallizer for growth of large crystals on oriented planar crystal seeds. The equipment possesses a system for automatic saturation of growth solution under constant hydrodynamic conditions. The first experimental results of growth of LATGS single crystals doped with $\mathrm{Pt}^{4+}$ ions confirm our expectation of high homogeneity and structural perfection of the grown LATGS/Pt(IV) crystals which are suitable for infrared detectors.

The research was supported by project No: S2067204 of the Academy of Sciences of the Czech Republic. 1. Whatmore R.W.: Rep. Prog. Phys. 49 (1986) 1335 2. Novotný J., Prokopová L., Micka Z.: J. Crystal Growth 226 (2001) 333

Keywords: CRYSTAL GROWTH, FERROELECTRICS , CATALYSIS

\section{Acta Cryst. (2002). A58 (Supplement), C168 \\ CRYSTAL GROWTH IN THE DIRECTED SOLUTION FLOW BY IN SITU AFM-OBSERVATIONS}

N.N. Piskunova

Lab. of Experimental Mineralogy Institute of Geology Ural Division of Russian Academy of Science 54, Pervamayskaya St. SYKTYVKAR 167982 RUSSIA

The flow direction of nutrient solution, its rate and supersaturation determine equilibrium surface morphology, growth rates, dominant mechanisms etc. $[1,2]$. We show the results direct observations by using atomic-force microscope (AFM) of a topographical changes on the sodium chloride and potassium dihydrogen phosphate crystal surfaces, which grow in the directed nutrient flow. So on the face (101) potassium dihydrogen phosphate the results of the observations demonstrate an example, when the solution flows against of the movement of growth steps, which originate, at least, from three active sources. With time, one of them, growing higher with the solution current, becomes a leader. The structure of its top is a dislocation source with hollow core at the centre. We earlier received equations for steps kinetic coefficient [3] and supersaturation on the growing surface. Being necessary for their calculations, steps growth tangential rate and tangent of hillock slope, can be obtained by the AFM-images with high accuracy. Evolution of steps kinetic coefficient along the line, connecting the tops of the competing hillocks, was shown during the time. At the end of the experiment, steps kinetic coefficient of the dominating hillock is considerably increasing.

The work was supported by RFBI (grant 00-15-98485 and 02-05-64688) and INTAS (grant 99-0247)

References

1. A.I.Glazov, E.B. Treivus, V.V. Mikhailov, Proceedings of the Russian Mineralogical Society 5(2000) 95.

2. A.A. Chernov, L.N. Rashkovich, I.L. Smolskiy et al., Growth of Crystals 15(1983) 43. 3. A.M. Askhabov, N.N. Markova, Proceedings of the Institute of Geology KSC UD RAS 90(1996) 194.

Keywords: FLOW, AFM, STEPS KINETIC COEFFICIENT 